\title{
Design of vertical members in large-span steel structures: Can relevance of seismic actions be exceeded on account of indirect fire actions?
}

\author{
J. Č. Kolšek* , P. Češarek \\ University of Ljubljana, Faculty of Civil and Geodetic Engineering, Jamova 2, SI-1115 Ljubljana, Slovenia
}

\section{A R T ICLE INFO}

Keywords:

Steel

$\mathrm{RC}$

Eurocodes

Indirect fire actions

Seismic actions

Long-span structures

Earthquake actions

Restrained thermal deformation

\section{A B S T R A C T}

Effect of lateral actions evolving from restrained thermal expansions of horizontal structural elements (beams, slabs) on stability of vertical elements (columns, walls) of fire-engulfed buildings remains unaddressed sometimes in engineering practice. Discussion with engineers has revealed that two reasons may contribute most to such design inconsistency. The first is premature assumptions that the effects of these actions can not be sufficient to exceed the effects of other lateral design actions, especially if for the same building considerable seismic influences are also expected. The second reason is the fact that, according to the present version of Eurocodes, these actions need not be addressed specifically if the design is carried out under standard fire curve. This curve, however, is still applied often in practice. For certain vertical members, such as the ones positioned somewhere within the middle of fire compartments, indirect lateral fire actions may indeed be negligible, e.g., due to partial or complete balancation of these actions in fire evolving simultaneously at two opposite sides. However, more pronounced effect might be observed for vertical members at the boundary between a fire-engulfed and a neighbouring cold-side compartment, especially in steel or RC buildings with larger horizontal spans prone to striking lateral thermal elongations. While such structures represent a fair share of existing building stock (they are common, e.g., in prefabricated industrial and commercial buildings), this problem deserves a special attention. In this paper two real one-storey large-span halls are analysed for confirmation of the above hypothesis. Each of them comprises two structurally connected units, i.e. one RC- and the other steel-framed, where fire is assumed to engulf the steel-framed unit. Stability of the 'cold-side' RC columns at the boundary between both sectors is discussed and for the latter indirect fire actions from the connecting fire-engulfed steel members are found to be of a comparable or a greater size to effect of moderate-size seismic actions. The greatest effects of the observed fire actions are found at average steel temperatures below $400^{\circ} \mathrm{C}$. This is a rather low temperature expected to be achieved (sooner or later) in most fire-affected steel elements with or without fire protection. At the same time, as in this paper also proven by results of exact visco-plastic structural computations, this is also a temperature at which no pronounced creep strains yet evolve in steel within time frames relevant for common structural fire analyses. In addition, the paper also shows that these conclusions would not change for other variations of the discussed two buildings where other possible kinematic boundary conditions were applied at the ends of the steel members or other possible thermal boundary conditions were assumed along their longitudinal surfaces. At most, the observed indirect fire effects would only increase further in these cases. Thus, at least for structures of a similar type (i.e. one-storey frame structures of horizontal spans of similar size and materials), the authors propose that the discussed lateral indirect fire actions are not dismissed from any design procedure regardless of the expected fire scenario as long as steel is allowed to heat to moderate temperatures (around $400^{\circ} \mathrm{C}$ ). In the last part of the paper the authors also discuss possible change of these findings for multi-storey frame structures and/or frame structures of other spans. However, for these (and other possible) structural types, a more detailed further investigation is proposed.

\footnotetext{
${ }^{*}$ Corresponding author.

E-mail adress: jerneja.kolsek@fgg.uni-lj.si (J. Č. Kolšek)
} 


\section{Introduction}

Buildings with long-span steel- or RC-framed structural systems are found frequently within building sector. During a fire in such buildings, high compressive longitudinal stress may develop in their horizontal structural elements (beams or plates) because of their span and pronounced tendency for thermal expansions. The impact of such fire actions may be negligible for connecting adjacent vertical elements (columns, walls) if these are positioned somewhere in the middle of the affected fire compartment. This is because same-type horizontal members are often connected to the mid-compartment vertical members symmetrically. Thus, all potential additional shear and bending forces that could evolve in the latter on account of restrained thermal elongation of the former get more or less eliminated. On the contrary, the vertical members at the boundary of fire compartments get affected unilaterally. Often, however, the problem of these elements remains unaddressed in the engineering practice. Discussions with engineers has revealed that two reasons may contribute most to such design inconsistency:

- Premature assumptions that indirect fire actions of the fireengulfed fire compartment upon the adjacent cold-side structure of neighbouring compartments can not be sufficient to exceed their structural resistance needed otherwise to meet the criteria of other design conditions, e.g. seismic conditions. Such conclusions are especially common if the building is built in a geographical region with moderate to severe seismic activity.

- The fact that these forces, as stated in [1] (see Section 4.1(4) of this standard), need not be calculated if the design is carried out for standard fire conditions. At the same time standard fire should be assumed automatically if no other specification is given in requirements for structural fire resistance by the designer of the building's fire safety [1] (see Section 2.3(3) of the standard). Such occasions are not rare in practice.

To challenge the validity of the above assumptions this paper presents a case of a typical large-span industrial hall originally designed as an RC prefabricated building but later extended with an additional steel-framed division. In the paper, a fully-developed fire is said to take place within the steel-framed extension and the effects of indirect fire actions on the structure of the cold-side RC-framed unit are monitored closely. Then, these are compared against the effects of the expected seismic forces. For calculation of the latter, a standard modal analysis is used. For fire analyses, however, a detailed performance-based solid-FE numerical model is engaged instead of an alternative simplified method. This is a necessity originating from restrictions of the simple procedures what will be put into a broader context in what follows. Below only procedures for steel struc- tures will be discussed as relevant for this paper but similar conclusions could be drawn for RC structures as well.

Fire analyses of steel structures are, without noticeable loss of precision of the calculation, normally divided into two computationally unconnected parts, i.e. thermal and mechanical analysis. In attempt for solving both of them time-efficiently, simple member-analysis procedures of EN 1993-1-2 [2] are consulted sometimes by the engineers in their everyday practice. As already implied by their name, in these procedures the entire structural system is first disassembled to individual structural elements (e.g. columns, beams, slabs ...) and then thermal and mechanical response is calculated individually for each of them. Firstly, thermal analysis is performed. This is based on the assumption that each member is heated uniformly along its length and across its cross-section. Thus, simple analytical forms can be used for calculations of the corresponding crosssectional temperature (see e.g. Annex A of EN 1993-1-2 [2]) bearing in mind restrictions of their validity. Secondly, in the mechanical analysis, suitable boundary conditions are first assigned to each member following the type of between-member connectivity. Time-dependent changes in these conditions are not accounted for but only conditions valid for time $t=0 \mathrm{~s}$ are followed. The effects of hindered axial or in-plane temperature deformations are neglected additionally. Such assumptions allow us to conclude that internal forces of structural elements are also unchangeable over time and can be, thus, determined using simple structural analysis at the start of the fire $(t=0 \mathrm{~s})$. The internal forces of each member, calculated in this way, can then be finally compared against their fire resistance determined as instructed by the standard (see e.g. Sections 4.2.3 and 4.2.4 of EN 1993-1-2 [2]). Ultimately, connections can be also checked separately, e.g. following simple instructions of Appendix D of the standard [2].

The alternative advanced procedures follow the main idea of removing some or all of the restrictions of the simplified procedures. These methods are based on the precise equations of the theory of heat transfer and the theory of geometrically and materially non-linear solid mechanics. As a rule, such equations can only be solved numerically, where presently finite element method seems to be chosen most frequently. In the standard [2] no specific advanced fire-analysis procedure is offered, yet many corresponding proposals can be found in other available literature. Depending on the desired accuracy of mathematical descriptions of structural geometry, here the most suitable model can be chosen from a variety of proposals of different beam models (e.g. [3-12]), shell models (e.g. [13-17]), and solid models (e.g. [18-25]). Normally, the solid models are the most sophisticated and the most accurate. Nevertheless, they are often also connected to the highest level of the problems with the models' convergence originating from either geometrical or material instabilities (global buckling, surface wrinkling, 
local buckling, contact slips, material softening). Thus, they are sometimes found to have a lower computational efficiency. Moreover, a further refined selection among the available advanced models can be made in terms of their material descriptions. In this respect, the models mainly differ on whether the creep strains of steel are included implicitly in the material submodel (cumulatively with plastic mechanical strains) or they are accounted for explicitly (creep strains are separated from mechanical plastic strains). The former approach is less accurate, and its additional limitation is that it is only valid for certain heating rates, thus, for certain fire scenarios (e.g. if the material submodel as proposed in Eurocode[2] is used the applicability of the procedure is restricted to rates of $2-50 \mathrm{~K} / \mathrm{min}$ ).

The paper consists of four main sections. Following introduction in Section 1, Section 2 is dedicated to a detailed presentation of the case study along with explanation of the methods of investigation. In Section 3 the main results of the investigation are shown. In Section 4 a generalisation of these results is also discussed for different possible structural and fire conditions. Finally, conclusions are summarised in Section 5.

\section{Research significance}

The most basic principle of ensuring fire safety of buildings follows the idea that each building is to be divided into a certain number of fire compartments, which should then be designed so that the fire (when/if it occurs) would not spread from one compartment to another for a certain period of time. In design of the building's load-bearing structure as per Eurocode, when dealing with the so called fire design situation (i.e. situation when one of the compartments is said to be engulfed in a fire), simplified member-analysis procedures are then often applied in practice for determining fire resistance of structural members inside this compartment. As already discussed in the previous section, these procedures base on two general assumptions neglecting possible fire-induced changes of kinematic boundary conditions of members and the influence of their axial or in-plane hindered temperature deformations. It is now known, that both assumptions are rather daring and that a special effort needs to be put into the question of their validity regarding the specificity of the case under our consideration. This is probably why in Eurocodes the use of such simplified procedures is limited to design under standard or (related) parametric fire conditions, for which so far the safety of the two assumptions has been validated most frequently. Rodrigues et al. [26], for example, performed a large number of high-temperature tests on hinged compressed steel bars having different slenderness values, load eccentricities and levels of restraint to axial elongation. This investigation concluded that neglecting the effects of thermal axial restraint may result in overestimation of fire resistance of steel columns. Another example is reserach of Feng and YanPing [27] who investigated fully restrained beams in a standard fire. They came to similar conclusions although the effects of restrained elongations seemed to have a more important role on early-stage behaviour of the beam but less on the time (temperature) of its final failure. Restrained steel beams of different level of end restraint and in different fire conditions were discussed, e.g., in [27-30]. Moreover, the undeniable importance of indirect fire actions in fire-affected structures has also been proven within a number of European and other research projects, results of which can be found, e.g., in [31-33]. Solutions for proper inclusion of restrained thermal deformations into engineering calculations were also proposed in these projects.

While the primary focus of the above mentioned investigations lies on the effect that fire-induced restrained thermal deformations have on the fire-engulfed (the expanding) structural elements themselves, to the authors' knowledge, little or no evidence exists so far regarding their effect on structural integrity of adjacent parts of the structure belonging to neighbouring (cold-side) compartments. The question, thus, remains whether these as well could be affected importantly by indirect fire actions of the fire-engulfed compartment or is the structural design of the latter always indisputably governed by other relevant design situations, such as seismic and permanent. This is the primary focus of the present paper. One storey buildings with long-span steel/RC-framed structural systems are discussed primarily for this purpose due to their large horizontal span and high material tendency for thermal elongations. With these type of structures one could reasonably expect that the observed impact will be maximized. Since such structures represent a fair share of existing building stock (they are common, e.g., in prefabricated industrial and commercial buildings), the present research is considered as of high research significance.

Effects of the explored fire actions are compared against effects of the expected moderate-size seismic forces in this paper. Such comparison helps making our illustration of the significance of these fire forces vivid and closer to all (not only appointed structural fire) engineering practitioners.

For fire analyses of this paper, as discussed in previous section, a detailed performance-based solid-FE numerical model is engaged. Two fire curves are implemented here, which are, in their relevant parts, found representable of actual fires that could potentially evolve in the discussed buildings. With one of these curves heating of steel below the limit of $2 \mathrm{~K} / \mathrm{min}$ is expected. Among scholars, this limit is well known as the limit below which the effects of high-temperature creep of steel can not be described suitably by a material submodel where creep strains are treated implicitly together with plastic mechanical strains, such as e.g. in the Eurocode model (see [2], Section 3.2.1(1)). Thus, in our model, the effect of creep are, instead, described explicitly. This essentially enables analyses of the calculated indirect fire forces also from the perspective of ma- 


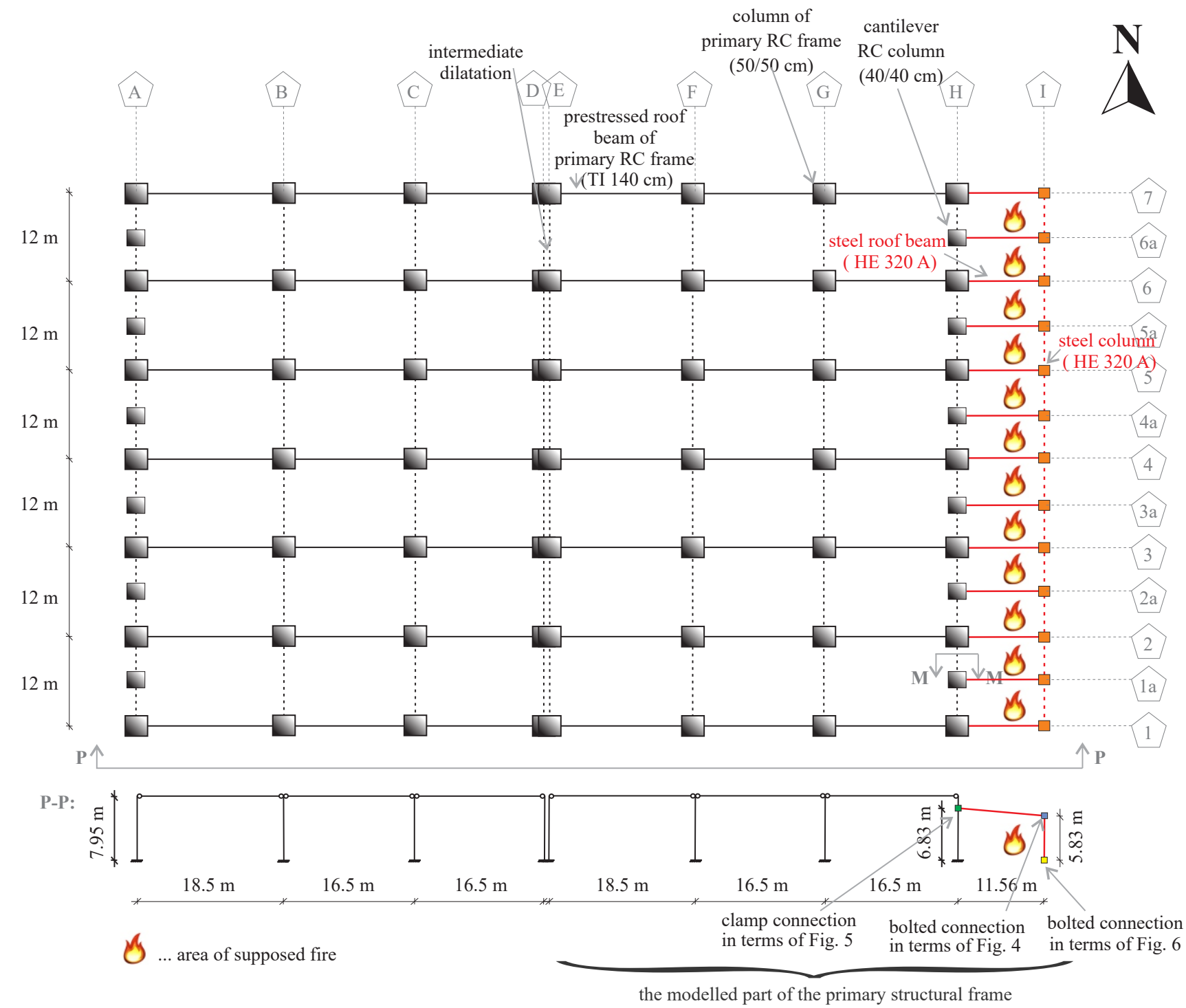

Fig. 1: Scheme of the primary structural system of the analysed buildings.

terial creep and contributes importantly to final suggested generalisation of the collected findings to other possible fire scenarios. At date such generalisations are difficult to find in available publications as are also implementations of explicit-creep solid structural models.

Explicit-creep solid structural models, as used in this paper, are considered to be of the highest precision but are also complex and computationally demanding. Thus, they often try to be avoided in everyday engineering practice. Generalizations of research findings collected with these models are therefore even more important, as these can offer considerable support to practitioners in assessments of validity of the assumptions of simplified design procedures regarding specifics of the building under their consideration.

\section{Case study and methods of investigation}

\subsection{The hall}

Let us consider a mixed steel-RC structural system as shown in Fig. 1. This is the load-bearing structure of two identical production halls located somewhere in the north-eastern part of Slovenia (region with moderate seismic activity). Each hall consists of two structurally connected units: (i) the RC-framed unit (Fig. 1, the black-coloured part of the scheme), which is the old unit built already in 1980's, and (ii) the steel-framed unit (Fig. 1, the red-coloured part of the scheme) representing the new extension built recently. The data provided below are summarized from the stability-design documentation of the two buildings which was kindly submitted by their owner. Only data relevant to this survey is shown. Other information is not disclosed at request of the owner. 




Fig. 2: Detail of the REI90 wall between the old and the new part of the building, view M-M (see Fig. 1 for denotations of the view $\mathrm{M}-\mathrm{M})$.

\subsubsection{Building envelope}

The roof and the facade of the RC-framed divisions of both buildings is covered by the same type sandwich panels and the same goes for the roof of their steel-framed units. Both buildings, however, differ in the design of the facade of their new extensions. In the first building this is fully closed by selected facade panels but in the second building the facade of the extension is left opened. Correspondingly, in this paper the first hall will be referred to as the 'FCE' building (the 'fully-closedenvelope' building) and the second will be notated as the 'SOE' building (the 'semi-opened-envelope' building).

\subsubsection{Fire compartmentation}

The steel- and the RC-framed unit of the halls are organized as individual fire compartments separated by fire-resistant wall panels (Fig. 2).

\subsubsection{RC-framed part of the structure}

The RC part of both halls is of a skeletal prefabricated type. It consists of a series of identical double ${ }^{1}$ frames in intermediate distance of $12 \mathrm{~m}$ which are considered as the primary structural system of the unit. Each frame consists of three pre-stressed roof beams (type TI140), which rest on columns of 50/50 cm cross-section through their respective pin-type bearings. Additional vertical structural elements of the east and the west outer wall of the RC-framed unit are cantilever columns of $40 / 40 \mathrm{~cm}$ cross-section which serve to support the wall panels.

\footnotetext{
${ }^{1}$ The term 'double' refers to a set of two identical frames that are separated by an intermediate dilatation (Fig. 1).
}

The elements are made of concrete C35/45 and their longitudinal and transverse reinforcement is of type B400.

Fig. 3 shows steel reinforcement of the RC columns of 50/50 $\mathrm{cm}$ cross-section which are positioned at the boundary between the RC- and the steel-framed building unit.

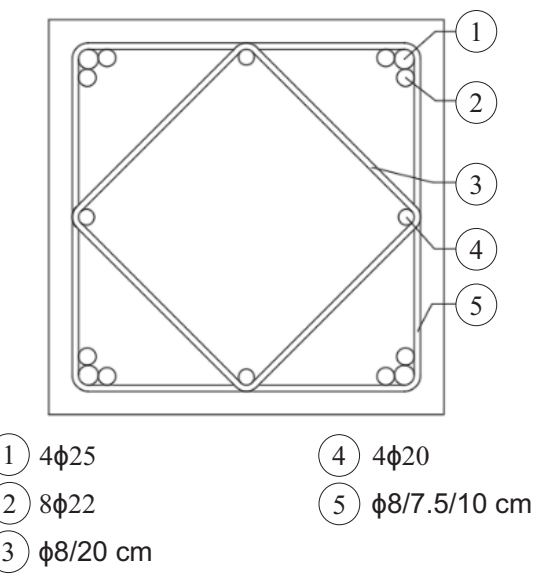

Fig. 3: Reinforcement of the RC columns of $50 / 50 \mathrm{~cm}$ crosssection positioned at the boundary between the RC- and the steel-framed building unit.

\subsubsection{Steel-framed part of the structure}

The extension to the east side of the old part of each of the two buildings is steel-framed. Its primary load-bearing structural system is a series of frames in intermediate distance of $6 \mathrm{~m}$. Each of these consists of a steel column and a steel roof beam, both of which are of the HE320A type cross-section and connected to each other by a bolted end-plate connection shown in Fig. 4. On its other end each of the steel roof beams is anchored to an RC column of the eastern outer wall of the old part of the building using a steel rod and a steel clamp as shown in Fig. 5. The base part of each steel column is connected to an RC foundation as shown in Fig. 6. Exact locations of connections shown in Fig. 4-6 within the global structural system can be observed in Fig. 1.

The structural steel is of quality S355 J2 except for the steel of the clamp which if of type S235. The bolts are of grade 8.8. Except where specifically stated otherwise (i.e. in cases discussed in Section 5.3 only) no fire protection is assumed to be applied on steel in this paper.

\subsection{The fire scenario}

Let us consider a fire scenario when flames engulf the steelframed fire compartment but do not spread toward the RCframed unit. Since our ultimate goal is a detailed discussion of structural response of the two buildings in such a situation, 


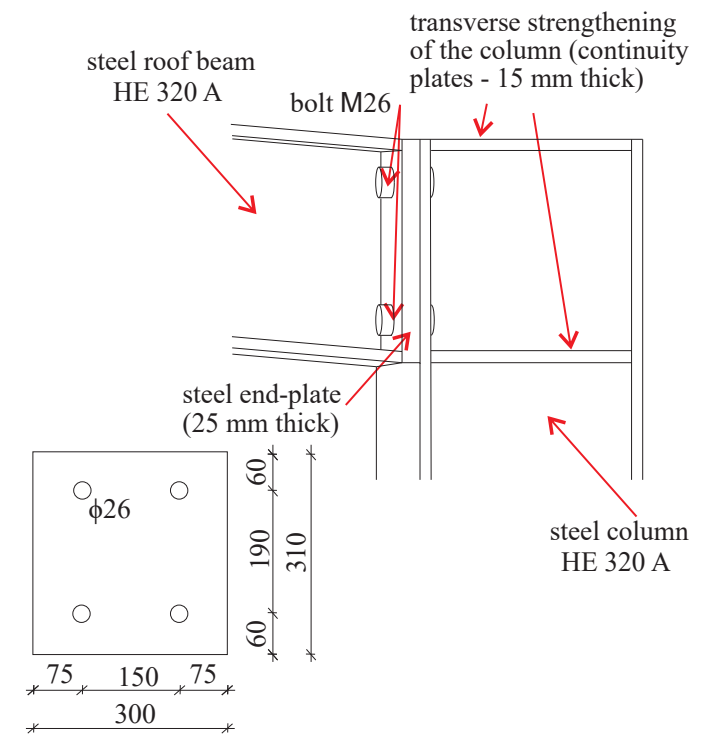

Fig. 4: Bolted end-plate connection between steel roof beam and steel column. Dimensions in the figure are in $\mathrm{mm}$.

for the sake of transparency of the paper, modelling of fire development will not also be discussed in details. Thus, a simplified yet reliable way of definition of the fire is necessary. Two nominal fire curves of EN 1991-1-2:2002 [1] are used for this purpose considering two types of the facade of FCE and SOE building. Although simple, these curves are judged suitable for the present investigation as explained below (see the next paragraph). Conditions of fully developed fire are assumed where at a specific time gas temperature is considered to be uniform throughout the entire fire compartment.

In the available literature the nominal fire curves of Eurocodes, with the ones suggesting the highest gas temperatures especially (e.g. the standard fire curve), are sometimes judged less appropriate in terms of their ability for modelling the heating phase of fires in buildings with larger compartments (such as in large-span buildings). Namely, because of the great volume of air filling the inside of such compartments, the fireinduced heat might result in substantially lower gas temperatures compared to those proposed by the standard and other high-temperature curves or such high temperatures might only evolve locally. This concern seems reasonable for large compartments with low or moderate fire loads while for higher fire loads, such as e.g. in large storages of highly combustible materials, the conclusion might be different. One of such storages was analysed recently in [34]. ${ }^{2}$. In this work a large-span hall for production and storage of expanded polystyrene (XPS) panels is discussed and a real fire that spread over one of the racks for storage of freshly produced panels (so called paternoster) in this building in 2013 is reproduced using a simulation in

\footnotetext{
${ }^{2}$ An extended version of this paper follows shortly (in preparation). Some additional results of the same investigation can be also found in [35]
}

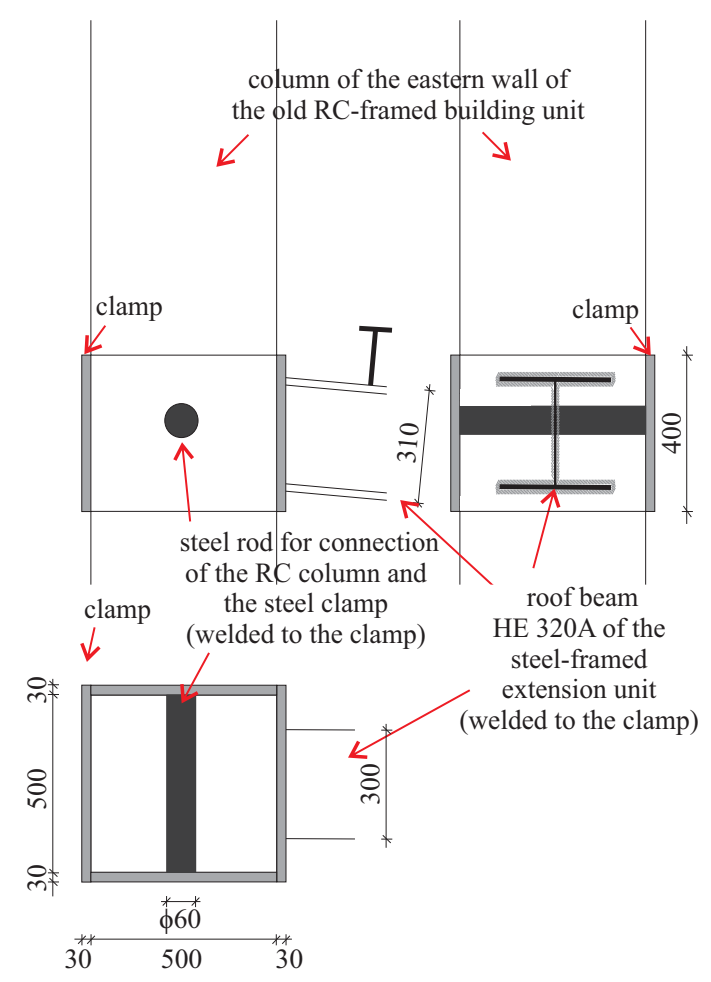

Fig. 5: Clamp connection of steel beam of the new building extension to RC column of the old part of the building. Dimensions in the figure are in $\mathrm{mm}$.

FDS (Fire Dynamics Simulator). Over the first 10 and the next 20 minutes of the simulated fire, the calculated gas temperatures are found to be $1100^{\circ} \mathrm{C}-1300^{\circ} \mathrm{C}$ and $600^{\circ} \mathrm{C}$, respectively. ${ }^{3}$ These temperatures are observed in a limited part of the affected compartment in this specific simulation (i.e. around the ceiling above burning paternoster of floor area of $6.5 \mathrm{~m} \times 2.9 \mathrm{~m}$ ). Yet, the affected area could easily be larger if a fire occurred, e.g., in a very similar adjacent building of the same company which is used for storage of manufactured XPS panels exclusively. Here, the amount of stored panels can be significantly higher when all of its storage capacity is exploited.

Considering the observations above, the heating regime of standard fire curve obviously fits well within the range of temperatures that can be reasonably expected in fires of large-span buildings with higher fire loads (Fig. 7). Thus, this curve will be used for modelling the fire in FCE building. However, temperatures will most probably be somewhat lower in the fire in SOE building because of the constant unrestrained inflow of cold external air (recall that no facade panels are covering the structure of outer walls of the steel-framed unit of this building). Hence, the external fire curve will be used instead in this case (Fig. 7). In reality, of course, the real fires might not fol-

\footnotetext{
${ }^{3}$ These results coincide well with gathered reports of eyewitnesses of the fire as well as with microscopic inspection of samples of structural steel and concrete gathered from the burnt-down building.
} 



Fig. 6: Connection between steel column and its RC foundation. Dimensions in the figure are in $\mathrm{mm}$.

low the flow of selected two curves exactly. Yet, this could only be important if, on account of that, considerably different creep strains could evolve prior to achieving the critical steel temperature, i.e. temperature at which the relevant indirect fire actions will be observed in the simulation. Pronounced creep could namely affect the values of these actions. However, this concern is irrelevant for the present investigation as will be shown later in the paper.

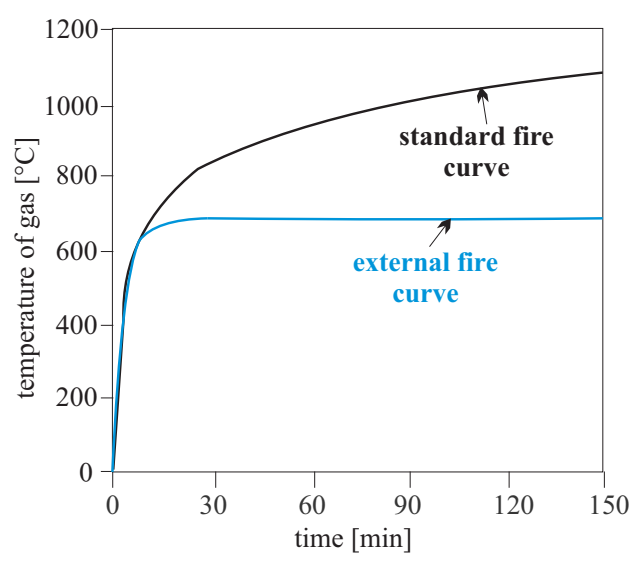

Fig. 7: Selected nominal fire curves.

The second concern regarding the Eurocode's nominal fire curves, also often exposed in literature, is the fact that in ev- ery realistic fire the temperature of gas will start to decrease at some point. This fact is neglected with a nominal curve. Nevertheless, the ultimate goal of this paper should be recalled once again. This is purely to test the hypothesis that in some cases of large-span buildings effects of indirect fire actions could be more relevant for the design of vertical structural elements as the effects of seismic actions. In this respect, cooling phase of the fire could only be important if such great effects of fire actions were only found at steel temperatures that are not likely to be achieved in realistic steel structures prior to their collapse or prior to them entering the cooling phase. Yet, this is not the case as the paper shows.

\subsection{The fire-analysis model}

For the halls under our analysis, it could be expected that during fire significant additional lateral forces and bending moments would develop in the horizontal steel members due to their hindered thermal elongation. These may also variate over time due to material and local stability changes in structural connections and elsewhere. Although these forces might not seem important at first glance and may even affect favourably the steel part of the structure, possible unfavourable effects are to be expected in terms of the connected RC structure. This must be checked by a thorough calculation.

In simplified member-analysis procedures, as explained before, the effects of constrained thermal expansions and changes in boundary conditions are neglected. Thus, such methods can not be engaged in our case. Among the corresponding modelling alternatives, a robust 3D solid-FE model will be used featuring one essential advantage, i.e. enabling precise geometrical descriptions of between-member connections ${ }^{4}$. The latter could influence the results pronouncedly. Furthermore, in terms of material descriptions, a material submodel with excplicit consideration of creep of steel will be engaged. Moreover, due to: (i) the correct symmetrical floor-layout of the structure (Fig. 1) and (ii) the assumption that at a specific time of the fire the gas temperature is distributed uniformly throughout the entire fire compartment, it is expected that the response of the structure in our computations will be planar. Thus, modelling typical frames, i.e. frames along the axes 1-7 (see Fig. 1 for denotation of axes), can be judged sufficient for the analysis instead of modelling the entire structure. The models were composed in the FEMA environment ABAQUS where each model comprises of two computationally separated steps as described below.

Note that only model of the frames in one of the main axes $1,2, \ldots, 7$ will be discussed in what follows. The frames along the subaxes $1 \mathrm{a}, 2 \mathrm{a}, \ldots, 7 \mathrm{a}$, where the steel part connects to the

\footnotetext{
${ }^{4}$ Alternative 1D or 2D models for description of the analysed structure could also be used instead if suitable measures were undertaken along with them for compensation of the effects of deformable connections (similarly as, e.g., in [36-39]).
} 
cantilever RC column of 40/40 cm cross-section, will not be analysed because the relevance of indirect fire actions vs. seismic actions is straightforward in these cases ${ }^{5}$.

\subsubsection{Step 1: Thermal response analysis}

The 1st (thermal) step of the analysis is set to be performed as a standard Fourier's heat conduction analysis and is conducted entirely by using the built-in tools of Abaqus. DC3D20 (20node quadratic heat transfer brick) finite elements are used for discretization of all of the assembly components (beam, column, bolts, end-plate, clamp, continuity plates). Within the heated region of the structure, the size of the edge of an individual element in the mesh is less or equal to $2 \mathrm{~cm}$ in the longitudinal direction and $0.7 \mathrm{~cm}-1 \mathrm{~cm}$ in the transverse direction (see, e.g., Fig. 8.) Simple radiation and convection boundary conditions are applied in terms of provisions of Eurocodes on all outer surfaces of the structure. The exception are surfaces that are (within the real building) in contact with roof and (for FCE analysis only) facade panels. For surfaces of elements, which are in the assembly initially in contact, it is assumed that they remain in contact throughout the whole duration of the fire (only for thermal analysis). A consistent heat transfer through these surfaces is achieved by tying the corresponding parts of the meshes of the two parts in contact. Thermal properties of steel and RC and their temperature dependence are taken as proposed in EN 1992-1-2 [40] and EN 1993-1-2 [2]. Initial temperature of the frame is set as $20^{\circ} \mathrm{C}$.

The final result of the analysis is the time history data of nodal temperatures of all structural members of the assembly.

\subsubsection{Step 2: Structural response analysis}

Step 2 is performed as general static analysis (implicit solver). Here the geometrical details of the individual parts and the assembly are taken from the 1 st step of the analysis and the structural elements are once again discretised by the built-in tools of Abaqus.

Two conditions were taken into account when selecting the finite elements for structural response analysis. The first is the ability of the model to capture global and especially local buckling shapes. To meet this requirement, quadratic finite elements were selected. The second condition is accuracy and robustness in describing the material nonlinear response, for which finite elements with reduced integration were selected, as recommended in the Abaqus user manual. Therefore C3D20R (20-node quadratic brick, reduced integration) finite elements are used.

In a fire, different parts of structural elements that are in contact initially, could separate during deformation and vice versa.

\footnotetext{
${ }^{5}$ The cantilever columns do not contribute significantly to structural loadbearing capacity against earthquake actions, thus, fire actions will be the most relevant for their design.
}

Therefore contact interactions need to be defined between the surfaces of such elements. To impose suitable contact algorithm, surface to surface contact interactions with finite sliding formulation are applied in the model. These interactions consider the shape of both surfaces in contact. A penalty method with linear pressure-overclosure relationship is used to enforce contact constraint. This method allows for some penetration of the surfaces in contact which reduces the computational complexity of dealing with a contact problem. The default value was selected for contact stiffness, which is set to 10 times a representative underlying element stiffness.

Time-dependent temperatures of the elements' nodes, calculated in the precedes thermal analysis, are imported to impose thermal load. In addition, a vertical mechanical load of 28.2 $\mathrm{kN} / \mathrm{m}$ and $4.3 \mathrm{kN} / \mathrm{m}$ is applied along the roof beam(s) of the RC and the steel frame, respectively (the self-weight of the beams is not included in these values). The load represents the weights of the roof panels and the secondary roof beams as well as the snow load. It is calculated in terms of accidental load combination as defined by EN 1990 [41] and the national annex SIST EN 1990:2004/A1:2006/A101:2009 [42].

For the material submodel of $\mathrm{RC}$ a simple isotropic linearelastic model as proposed in [43] is used with the elastic modulus of concrete being reduced by half $\left(E_{c}=1550 \mathrm{kN} / \mathrm{cm}^{2}\right)$ to account for the effects of concrete cracking on structural deformations. This seems as reasonable approximation since the $\mathrm{RC}$ part of the structure (including the boundary columns) is not affected by the fire directly but remains at ambient temperatures. Furthermore, for the material submodel of steel of bolts the model of Kirby [44] is engaged. In addition, for material description of other steel components, where consistent description of creep is desired, suitable algorithms are implemented using the user subroutine UMAT developed by the authors [21]. The basic theoretical framework of the latter is summarised below. Further details, including extensive validation of the routine, can be found in [21].

\subsubsection{The UMAT material submodel}

The UMAT material submodel used for purposes of this paper bases on the well-known 'principle of additivity of strains' (see e.g. [45]). Correspondingly, the total (so called 'geometrical') strain tensor $\varepsilon^{k}$ (upper-script $k$ denotes time station $t^{k}$ ) in a generic particle of the body is decoupled as follows:

$$
\begin{aligned}
\varepsilon^{k} & =\varepsilon^{k-1}+\Delta \varepsilon^{k} \\
& =\varepsilon^{k-1}+\Delta \varepsilon_{t h}^{k}+\Delta \varepsilon_{\sigma, e}^{k}+\Delta \varepsilon_{\sigma, p}^{k}+\Delta \varepsilon_{c r}^{k}
\end{aligned}
$$

In the above equation $\Delta \varepsilon^{k}$ denotes the increment of the total (i.e. geometrical) strain tensor in the time interval $\left[t^{k-1}, t^{k}\right]$. The latter can be written as the sum of the strain increments due to 


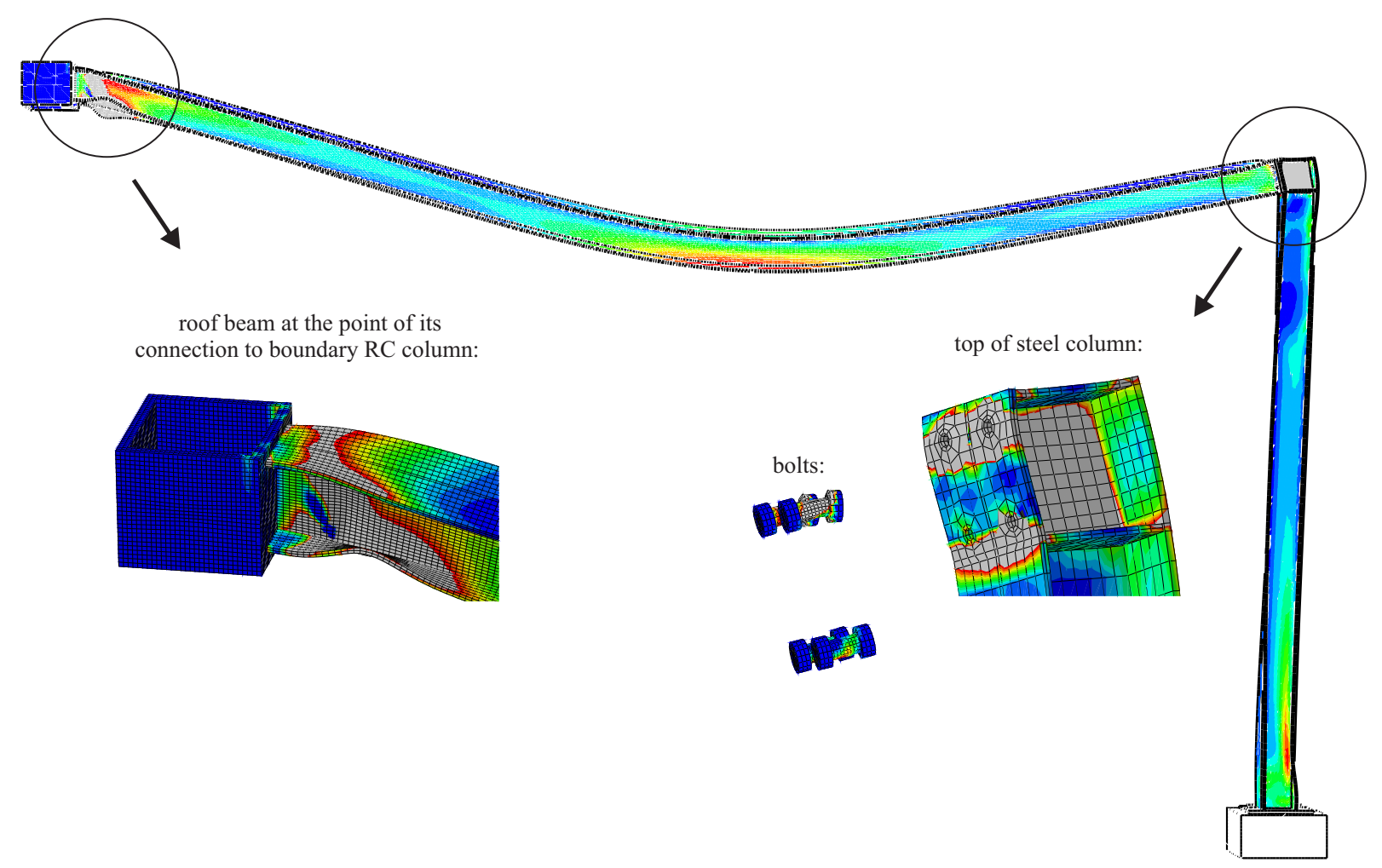

Fig. 8: FCE building: deformed shape of the steel part of the structure right before its collapse.

change of: (i) temperature, $\Delta \varepsilon_{t h}^{k}$ and (ii) stress. Stress-induced part can be decoupled further in terms of time-independent mechanical strains $\Delta \varepsilon_{\sigma}^{k}$, which splits to reversible elastic and irreversible plastic part, and time-dependent irreversible creep strains, $\Delta \varepsilon_{c r}^{k}$. In terms of thermal strains $\Delta \varepsilon_{t h}^{k}=\Delta \varepsilon_{t h}^{k} \mathrm{I}=\alpha_{T} \Delta T \mathrm{I}$ ( $I$ representing unit tensor), a proposition of [2] is used for calculation of the temperature-dependent unidirectional extension coefficient $\alpha_{T}$. For consideration of mechanical strains the classic Mises' plasticity submodel with isotropic hardening is engaged as proposed in [46]. In each time step of the calculation the equivalent (Mises) stress $\sigma_{M}$ is to be compared against the material yield stress to check the plasticity criterion. For these purposes, yield stress is calculated from the hardening model suggested by [47, 48]. Furthermore, for consideration of creep strains, the Williams-Leir's creep model is adopted from [49]. Following proposition of [50], coefficients for A135 steel are engaged here for the S235 clamp of the steel assembly and coefficients for SM50 are used for the rest S355 members.

\subsubsection{Stability issues}

Due to hindered thermal expansion of steel, localized instabilities appear during our structural fire analysis, such as local buckling of the web or flange of the beam. These instabilities reflect in numerical stability issues which can be solved by employing automatic stabilization controls in Abaqus. Auto- matic stabilization adds artificial viscous forces to the nodes of the finite elements that are not in equilibrium due to the instabilities. The total energy of these forces must be small enough so that the numerical damping does not affect the results of the analysis. The default settings for automatic stabilization control parameters proved to be optimal in our model. Furthermore, the second source of instabilities are the sudden changes in contact conditions, i.e. contact openings, slips etc. But they are less likely to cause numerical instabilities due to the choice of the contact algorithm. Nevertheless, if such numerical problems appear, they are as well solved by artificial damping.

\subsubsection{Validation of the composed model}

Similar modelling techniques as proposed for purposes of this paper have been engaged previously by the authors and these were verified and validated substantially in [21].

\section{Results and discussion}

\subsection{Response of the steel part of the structure}

With the numerical model, as described above, the fire response of the steel part of the analysed structure was first followed closely. For the FCE hall, this is shown schematically in Fig. 8. The figure shows the deformed shape of the steel structural part 




Fig. 9: Average temperatures of the web and both of the flanges of the steel roof beam as evolved in both buildings (calculated around mid-span of the beam).

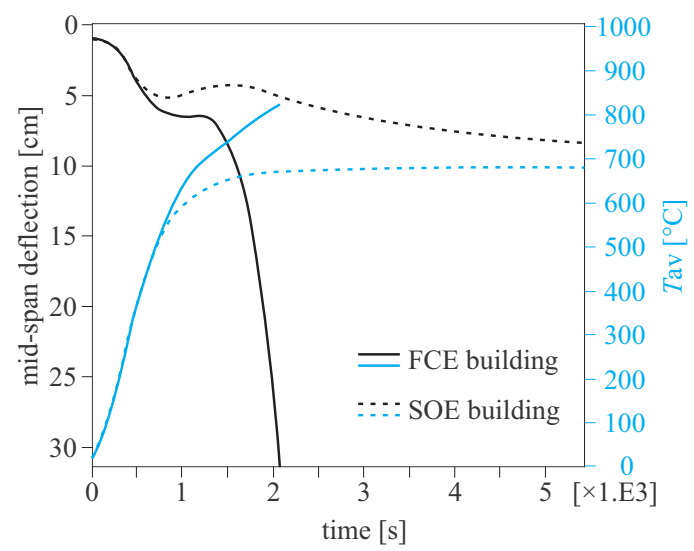

Fig. 10: Mid-span deflections of the roof beam and corresponding average cross-sectional temperature for the FCE (solid lines) and the SOE building (dashed lines).

of this building at time just before its collapse. In any particular material point the value of the cumulative plastic strain (i.e. plastic mechanical and creep strain) at this time is also given using a specified colour. The grey colour indicates the areas with strains greater than $2 \%$ (deformations at the yield point) ${ }^{6}$.

The area of pronounced material yielding that is in Fig. 8 seen clearly at the top of the steel column (region between the two continuity plates) is in the analysis formed first (approximately $75 \%$ of this area is formed up until $T_{\mathrm{av}} \approx 450^{\circ} \mathrm{C}$ where $T_{\mathrm{av}}$ is the average steel temperature of the beam's midspan cross-section $)^{7}$. Soon after, plastic strains are also formed around the perimeter of the upper two of the bolt holes $\left(T_{\mathrm{av}} \approx\right.$ $\left.400^{\circ} \mathrm{C}\right)$. Next, evolution of larger areas of material yielding are observed in the roof beam around its left end $\left(T_{\mathrm{av}} \approx 790^{\circ} \mathrm{C}\right) \mathrm{fi}-$

\footnotetext{
${ }^{6}$ Plastic strain of $2 \%$ corresponds to the start of material yielding as defined in [2] and holds true for any given elevated material temperature.

${ }^{7}$ Average temperatures as evolved in the beam of FCE and SOE building are shown in Fig. 9
}

nally leading to buckling of the lower flange of the beam and of the lower parts of its web $\left(T_{\mathrm{av}} \approx 830^{\circ} \mathrm{C}\right)$ in this region. Almost simultaneously, yielding is detected also in the upper bolts in the bolted beam-column connection. After these two bolts are fully plasticized $\left(T_{\mathrm{av}} \approx 840^{\circ} \mathrm{C}\right)^{8}$, the roof beam remains stable for some time which is the influence of the remaining loadbearing capacity of its left end as well as the compressive stress in the lower part of the beam's cross-sections. These evolve as a result of restrained thermal deformations. With time, however, a plastic hinge is formed around the beam's left end ${ }^{9}$ suddenly accelerating the deflections of the beam (Fig. 10) and soon implying collapse of this structural member ${ }^{10}$.

Similarly as for the FCE building, the above-described distinguishing events can be also detected in the analysis of the SOE building, obviously with the exception of those corresponding to $T_{\mathrm{av}}>680^{\circ} \mathrm{C}$ (the highest steel temperature achieved for the SOE building). Following lower fire temperatures, the structure does not collapse during the observed 90 minutes of the fire.

\subsection{Indirect fire actions affecting the cold RC part of the struc- ture}

In addition to a close follow-up of fire response of the steel part of the structure, an assessment of impacts of the latter on stability of the cold RC structure can be also performed using the presented model. These impacts are shown schematically in Fig. 11 as three time-dependent loads $(H, V, M)$. The latter were calculated by integrating stress across the cross-section of the steel beam in immediate vicinity of the steel clamp.



Fig. 11: Scheme of the three observed time-dependent actions $(H, V, M)$.

$H, V$, and $M$ can fluctuate substantially over time what is mainly a consequence of restrained thermal elongations of the

\footnotetext{
${ }^{8}$ The event of a full plastification of a bolt is declared when yield strains are evolved throughout the first entire cross-section of its body.

${ }^{9} \mathrm{~A}$ plastic hinge is said to be formed in the beam when yield strains of $2 \% 0$ or more are evolved throughout the first entire cross-section of the beam.

${ }^{10}$ The beam is said to collapse when the rate of its mid-span deflection $D$ exceeds the rate defined as limiting in standard fire experiments, see [51]: $(d D) /(d t)>\left(L^{2}\right) /(9000 d) \mathrm{mm} / \mathrm{min}$ where $L$ is the clear span of the test specimen (in millimetres) and $d$ is the distance from the extreme fibres of the cold design compression and tension zone of the structural section (also in millimetres).
} 
steel beam and change in its mechanical boundary conditions. See Annex A for more details. A completely consistent engineering approach would, thus, require us to divide the entire fire time into smaller intervals, within which these forces are approximately constant, and then check the load-bearing capacity of the observed RC columns within each such time section. However, since: (i) $H$ and $M$ only change their value during the fire but not also their direction and because (ii) these two forces both influence the column in the same manner (the maximal bending moments developed in the column due to these two forces are of the same sign), in this paper the check of the column is performed with only one combination, i.e. $\left(H_{\max }\right.$, $M_{\max }$ ). Index ' $\max$ ' here refers to the force value at the time when it is maximal. In contrary, to follow the principle of the 'safe-side' design, the value of $V$ is taken as minimal. See table 1 for details.

\begin{tabular}{rrrr}
\hline & $H_{\max }(\mathrm{kN})$ & $V_{\min }(\mathrm{kN})$ & $M_{\max }(\mathrm{kNm})$ \\
\hline $\begin{array}{r}\text { FCE } \\
\text { building }\end{array}$ & 19.7 & 27.5 & 208.5 \\
$\begin{array}{r}\text { SOE } \\
\text { building }\end{array}$ & 56.6 & 27.5 & 244.7 \\
\hline
\end{tabular}

Table 1: Combination $\left(H_{\max }, V_{\min }, M_{\max }\right)$ as used in analyses of FCE and SOE building.

In addition, results for $\left(H_{\max }, V_{\text {corr }}, M_{\text {corr }}\right)$ are also provided for a comparison. Index 'corr' here refers to corresponding values of the other two accompanying forces for the time when the force $H$ achieves its maximum value. See table 2 for details.

\begin{tabular}{rrrr}
\hline & $H_{\max }(\mathrm{kN})$ & $V_{\text {corr }}(\mathrm{kN})$ & $M_{\text {corr }}(\mathrm{kNm})$ \\
\hline FCE & 19.7 & 28.2 & 118.8 \\
building & & & \\
SOE & 56.6 & 33.8 & 238.4 \\
building & & & \\
\hline
\end{tabular}

Table 2: Combination $\left(H_{\max }, V_{\text {corr }}, M_{\text {corr }}\right)$ as used in analyses of FCE and SOE building.

\subsection{Comparison of the calculated effects of indirect fire ac- tions to the effects of seismic actions}

To enable a more tangible idea about the severity of the calculated $(H, V, M)$, Fig. 13-12 further show the corresponding maximum cross-sectional axial force $N_{\mathrm{x}, \mathrm{fi}}$ and bending moment $M_{\mathrm{y}, \mathrm{fi}}$ that evolve as a result of these actions in the connecting $\mathrm{RC}$ columns (i.e. columns along axis $\mathrm{H}$ of Fig. 1). In the figures, the calculated $\left(N_{\mathrm{x}, \mathrm{fi}}, M_{\mathrm{y}, \mathrm{fi}}\right)$ are placed within interaction diagram of the ultimate cross-sectional resistance of the columns and they are also set side by side cross-sectional forces $\left(N_{\mathrm{x}, \mathrm{se}}, M_{\mathrm{y}, \mathrm{se}}\right)$ representing maximum column forces caused by expected seismic actions. This comparison seems important since, in geographical areas with moderate and severe earthquake activity, seismic actions are often assumed as being by far the most relevant for the design of vertical structural elements of many buildings. For the two buildings discussed in this paper, however, the figures reveal that the effects of both discussed actions on cross-sectional forces are of a comparable size, thus, such conclusions can not be made a priori for this case.

Further details on the presented comparison of Fig. 13-12 are summarised below:

- For construction of interaction diagram of the column the material data provided in Section 3.1 were followed. For each of the observed load combinations, i.e. fire and earthquake, these were suitably modified using the following material partial factors: $\gamma_{\mathrm{c}, \mathrm{se}}=1.5, \gamma_{\mathrm{s}, \mathrm{se}}=1.15, \gamma_{\mathrm{c}, \mathrm{fi}}=1.0$, and $\gamma_{\mathrm{s} \text { se }}=1.0$ as ascribed in Eurocodes and its relevant Slovenian National Annexes.

- Seismic actions used for calculation of $\left(N_{\mathrm{x}, \mathrm{se}}, M_{\mathrm{y}, \mathrm{se}}\right)$ were calculated in terms of EN 1998-1:2004 [52] using modal analysis. The basic input data for the spectrum were as follows: ground type B, horizontal ground acceleration $0.125 \mathrm{~g}$, behaviour factor 2.5 . A complete quadratic combination CQC was used for modal combination.

- The reader should bear in mind that the high ultimate resistance of the analysed boundary RC column as seen in Fig. 13-12 is a consequence of the past overdesign of the old RC-framed part of the structure.

\section{Towards generalisation of gathered results: What to ex- pect in other structural and fire conditions?}

\subsection{Mechanical boundary conditions of structural steel}

Mechanical boundary conditions (BCs) at the end of each individual structural member could affect the extremes of forces $H, V, M$ substantially. For boundary conditions at the ends of the steel beam and at the bottom of the steel column this was explored and confirmed in [53]. In this work, different BCs were achieved by employing different variations of models of: (i) the steel clamp on the left end of the beam, (ii) the bolted beamcolumn connection and (iii) the foundation of the column. See Table 2 of the thesis for schemes of the tested models and Fig. 39-43 for corresponding results of $H, V, M .{ }^{11}$

\subsection{Thermal boundary conditions of structural steel}

The standard and the external fire curve, which were in this paper used in the analyses of FCE and SOE building, coincide

\footnotetext{
${ }^{11} \mathrm{~A}$ separate paper presenting these results in English is in preparation.
} 


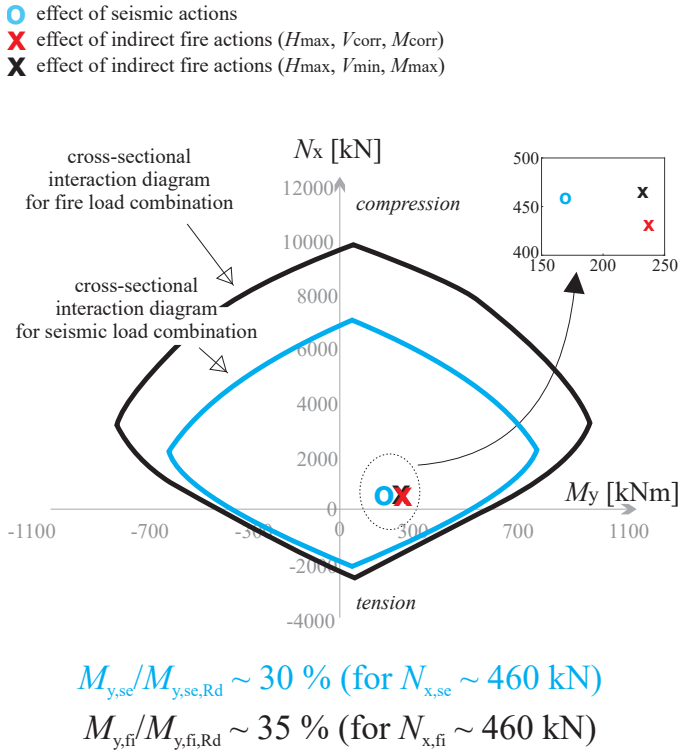

Fig. 12: SOE building: Combinations of axial and bending forces $\left(N_{\mathrm{x}}, M_{\mathrm{y}}\right)$ evolved in the critical cross-section of the observed boundary RC column. The axial force in the RC beam is approximately of the same value for the fire and seismic load combination and equals to roughly $460 \mathrm{kN}$.

almost exactly over the duration of the first 10 minutes of the described fire (see Fig. 7). Together with the fact that the structural system and its gravity loading is identical for both buildings, one could, thus, expect that within the first 10 minutes the indirect fire actions $H, V, M$ will also coincide for both buildings. Nevertheless, as clearly seen especially from the graph of force $H$ in Fig. A.20 (Annex A), this is not the case. The reason is in applied thermal boundary conditions. Recall that in the case of SOE building, the outer wall of the steel-framed extension of the building is opened (not covered with facade panels), so the same temperature conditions are prescribed on all sides of the column of this facade (uniform four-sided exposure). Because of this, the temperature field evolved along the cross-section of the column is symmetric. Thus, elongation only but no bending of the column is provoked on account of steel thermal deformations. As a result, the horizontal displacement at the top of the column is smaller in this case (Fig. A.22). In addition, the elongation of the column is also faster here as in FCE building because of the column's four-sided exposure (Fig. A.22). This causes more uplift of the connected roof beam and provokes more restraint to thermal elongation of the latter. Consequently, the axial force of the beam gets higher. The comparison proves great importance of thermal boundary conditions.

\subsection{Structures with applied fire protection}

Results presented in Section 4 refer to cases of FCE and SOE building under approximation that no fire protection is applied



Fig. 13: FCE building: Combinations of axial and bending forces $\left(N_{\mathrm{x}}, M_{\mathrm{y}}\right)$ evolved in the critical cross-section of the observed boundary RC column. The axial force in the RC beam is approximately of the same value for the fire and seismic load combination and equals to roughly $460 \mathrm{kN}$.

on the structure of their steel-framed extensions. In what follows, these two cases will be called the 'unprotected version of $F C E(S O E)$ building' for the sake of simplicity. In both cases the extreme values of actions $H, V, M$ are achieved at the average steel temperature below $400^{\circ} \mathrm{C}$. This means at temperature at which no pronounced creep strains are yet expected to evolve in steel within time frames relevant for common structural fire analyses. Correspondingly, these values would most probably remain almost unchanged if fire protected versions of the same buildings were discussed. This would be so, obviously, as long as steel behind the fire protection was allowed to heat to such temperatures $\left(400^{\circ} \mathrm{C}\right)$ before structural collapse or before entering the cooling phase. To support this assumption, additional numerical analyses were performed and they are summarised below.

In the additional analyses, the structural response of FCE building is modelled again, this time by applying three different slower regimes of the rise of steel temperature, see Fig. 14. These are three possible regimes for when the structure was protected by a reactive intumescent coating (observe the steel temperature evolution of such steel members, e.g., in [54]). We will denote them as fast, moderately-fast, and slow heating regime. The corresponding results in terms of the indirect fire action $H$ are shown in the same figure. The latter clearly shows that the maximum of the calculated $H$ remains almost exactly the same for all of the three cases.

Furthermore, surprisingly, the corresponding graph of $H$ shown previously in the paper for the unprotected version of 
FCE buidling (Fig. A.20) seems entirely different at first glance. Nevertheless, the way how the efficiency of fire protection of steel is usually presented by their manufacturers (and how it was, correspondingly, modelled in this paper) should be emphasized at this point. I.e only the average temperature of the steel member is normally known for specific thickness of the insulation at specific time of the fire and only such information could, thus, be used in the simulations. This means that the graph of $H$ shown in Fig. A.20 is not suitable for the comparison as aimed at in this section because a precise calculation of flow of heat from fire-engulfed compartment into steel was used for its derivation. In other words: while temperature field inside the structural steel was approximated as constant at a specific time of the fire in three of the analysed fire-protected structural cases, such approximation was not made in the fire-unprotected case of Fig. A.20 but more precize thermal boundary conditions were applied. Judging by the conclusions of Section 5.3, the effect of this modelling distinctions undoubtedly reflected in the results of the calculation. Thus, to eliminate its influence and to only show the influence of material creep, the results for unprotected version of the structure need to be recalculated.

For purpose of recalculation of the unprotected version of FCE building the average steel temperature of the mid-span cross-section of the roof beam is calculated from the results of the original thermal analysis of this case and then this temperature is applied to steel of the redesigned model. The corresponding results are finally put side-by-side the results of the three fire-protected versions (Fig. 14). The comparison obviously confirms that the extreme value of action $H$ is approximately the same in all of the four cases proving negligible effect of material creep.

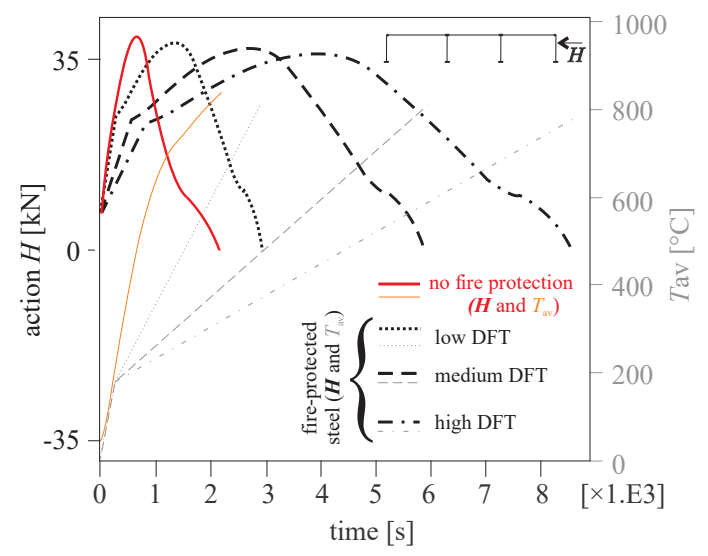

Fig. 14: Effect of creep on the calculated indirect action $H$ and applied steel temperatures.

\subsection{Other fire scenarios}

As discussed above, in analyses of the analysed buildings creep of steel has proven to have no meaningful effect on the extremes of the observed actions $H, V$ and $M$ because these extremes already evolved at steel temperatures below $400^{\circ} \mathrm{C}$. Hence, similar results could also be expected for any other possible fire scenario provided similar temperatures would evolve in steel prior to structural collapse or prior to entering the cooling phase. The reader should note that $400^{\circ} \mathrm{C}$ is a rather moderate steel temperature that is in fire expected to evolve (sooner or later) within the heating phase and prior to collapse of any steel structural member regardless of its utilization at room temperature (see, e.g., Table 4.1 of EN 1993-1-2), the obvious exception being those with excessive fire protection.

\subsection{Localised fires}

In the analyses of Section 4 it was assumed that at a specific time of the fire gas temperature was distributed uniformly over the entire fire compartment. Because of this assumption and due to correct floor-layout of the structural system, modelling only one of the primary structural frames (i.e. frames along axes 1-7 in Fig. 1) was sufficient. A model of the entire structural system would, however, also make sense if localised fire was also considered (e.g. if only one or only few of the steel frames was assumed fire-affected). It seems reasonably to expect that in such a case the effects of indirect fire actions would be even higher as in the previously discussed cases (effect of cold part of the structure would enhance horizontal structural stiffness in this case).

\subsection{Large-span $R C$ buildings}

Since not only steel but also concrete is a material prone to pronounced thermal expansions, high values of indirect fire action could also be expected in large-span RC buildings. On the other hand, because RC structural members are usually more massive and because concrete also has a lower thermal conductivity compared to steel, such action could perhaps only evolve in exceptional situations. The question is a subject of further investigation of the authors.

\subsection{Other building geometry}

The hall discussed in this paper was a one-storey building with a relatively low mass. Correspondingly, the calculated seismic actions were low as well. If a multi-storey building with a high mass was considered instead and/or the hall was built in a geographical region with severe earthquake activity, these forces could rise several times. Nevertheless, with a change of the geometry of the fire-affected steel part of the building, the indirect fire actions could change significantly as well. For example, preliminary analyses of the same hall as was discussed in this paper in which, however, the roof beams of the steel extension 

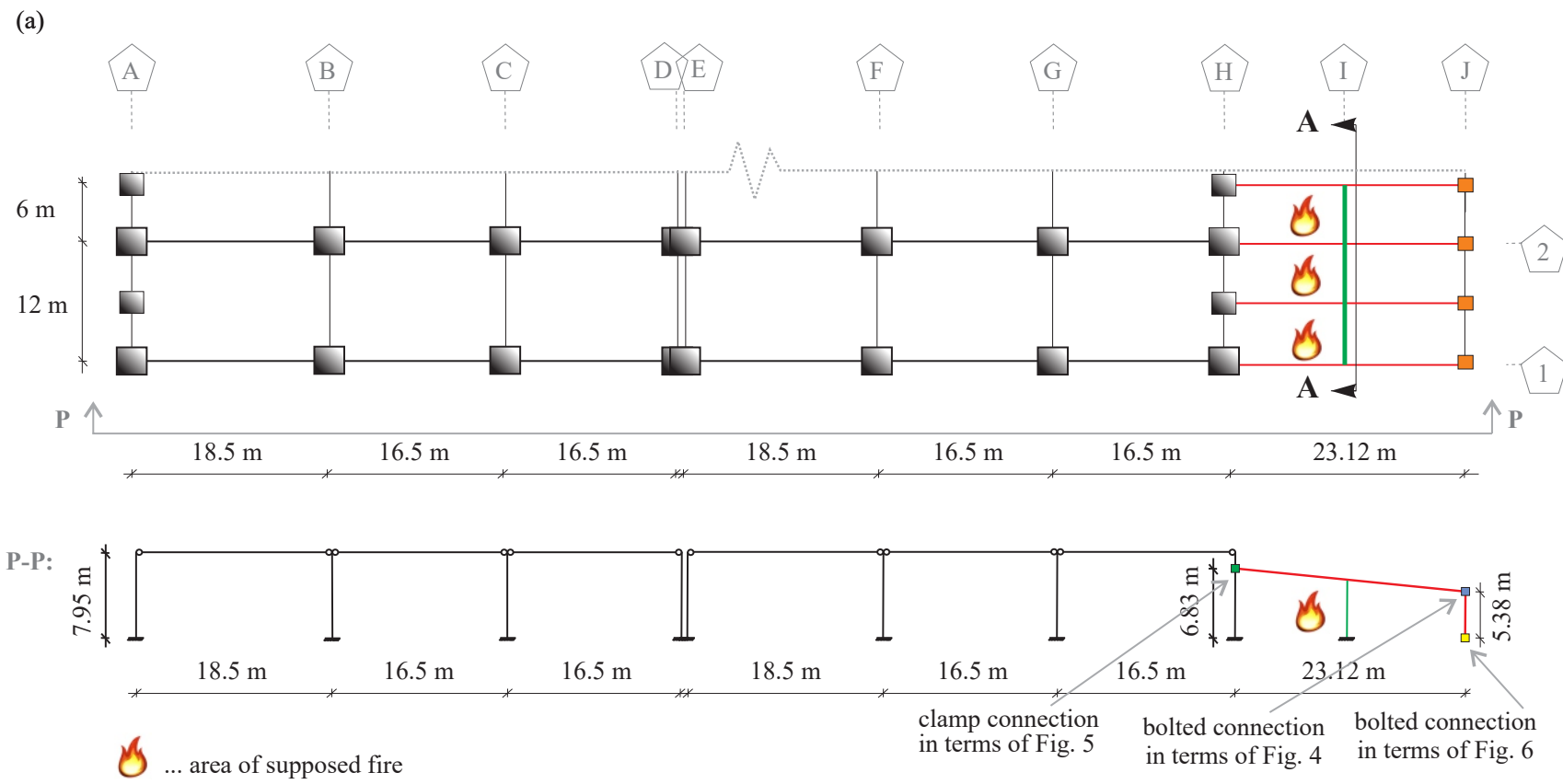

(b)

\section{A-A:}

(c)

\section{$76.2 \mathrm{kN}$}

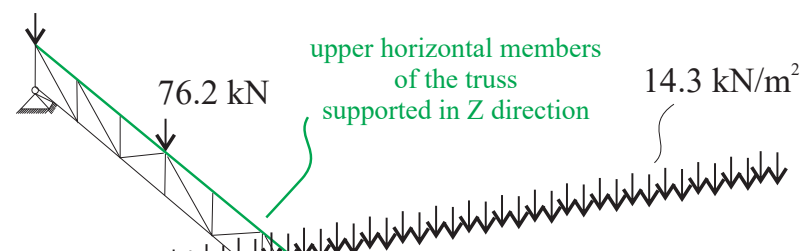

Fig. 15: (a) Scheme of a part of the primary structural system of the building with the steel beams of two-times longer span supported at their mid-span via a sliding connection towards a supporting truss. Shown is a part of the system corresponding to one supporting truss. (b) Supporting truss. (c) Model of the steel part of the structure as created in Abaqus (connecting RC frame is modelled as in previous cases).

would have a two-times larger $\operatorname{span}^{12}$ showed that the maximal value of force $H$ during fire could increase up to four-times in such a case, see Fig. 16.

Note that the above conclusions were drawn from results of the model as shown schematically in Fig. 15. Only one steel roof beam was modelled here for the sake of simplicity. The influence of the rest was represented by three point loads of $76.2 \mathrm{kN}$ magnitude. The truss was considered fire protected.

\footnotetext{
${ }^{12}$ Such a case was also checked by the authors at the time of the first design of the steel-framed extension unit when the steel beams were still planned to have two-times longer span and were supposed to be supported at their mid-span via a sliding connection toward a supporting truss (Fig. 15).
}

A moderately fast heating regime as already used in Section 5.3 (see Fig. 14) was assigned to the truss members for this purpose. Moreover, the two columns supporting the truss on its both ends as shown in Fig. 15(b) were not modelled explicitly since it was assumed that these columns are fire protected in the way that they do not deform significantly prior to collapse of the beam. The analysis was performed for standard fire conditions.

\section{Conclusions}

In fires of buildings, pronounced compressive longitudinal stress often develop in the horizontal structural elements, such 




Fig. 16: Action $H$ as evolved with time in FCE building with steel beams of two-times longer span.

as beams or plates, as a result of their constrained thermal elongations. The impact of such fire actions on the structural loadbearing capacity of connecting (adjacent) vertical elements may be negligible if these are positioned somewhere in the middle of the fire compartment because, in this way, these are affected symmetrically by these actions from opposite sides. However, the impact may be unfavourable for vertical members at the boundary between neighbouring fire compartments. Even more, it may be suspected that in some cases, such as in buildings with long-span steel-framed structural systems, these actions may be the most relevant for the design of these vertical elements - even when compared to effect of seismic actions. To check this hypothesis, a case study was presented in the paper dealing with a typical industrial hall located somewhere in the seismical active north-eastern part of Slovenia. In the past this hall was designed as an RC prefabricated building but it was later extended with an additional steel-framed division where the old and the new building unit were planned as two separate fire compartments. Analyses of fire scenarios, where flames were said to engulf the steel-framed extension of the building, showed that the effects of hindered thermal expansion of steel beams on the RC columns at the boundary between both fire compartments would be pronounced in such a case. In fact, they would be of a comparable size as the effects of the expected seismic actions or higher in some cases. In addition, the maximal values of these influences would evolve already at average steel temperatures below $400^{\circ} \mathrm{C}$. This is a rather low temperature expected to be achieved (sooner or later) in most fire-affected steel elements with or without fire protection. At the same time, as also proven by results of exact visco-plastic structural computations, this is also a temperature at which no pronounced creep strains would evolve yet in steel within time frames relevant for common structural fire analyses. In addition, the paper also showed that these conclusions would not change for other variations of the discussed buildings where other possible kinematic boundary conditions were applied at the ends of the steel members or other possible thermal boundary conditions were assumed along their longitudinal surfaces. At most, the observed indirect fire effects would only increase further in these cases. Thus, at least for structures of a similar type (i.e. one-storey frame structures of horizontal spans of similar size and materials), the authors proposed that the discussed lateral indirect fire actions are not dismissed from any design procedure regardless of the expected fire scenario as long as steel is allowed to heat to moderate temperatures (around $400^{\circ} \mathrm{C}$ ).

The hall discussed in this paper was a one-storey building with a relatively low mass built in a geographical region with moderate earthquake activity. Correspondingly, the calculated seismic actions were relatively low as well. If a multi-storey building with a high mass was considered instead and/or the hall was built in a geographical region with more severe earthquake activity, these forces could rise several times. Nevertheless, with a change of the geometry of the fire-affected steel part of the building, the indirect fire actions could change significantly too. An example was shown in the final section of the paper, where the roof beams of the previously discussed building were said to have two-times larger span. The relevant indirect fire actions increased four-times in such a case. For these (and other possible) structural types, the authors propose that a more detailed further investigation is performed in the future.

Because not only steel but concrete as well is a material prone to pronounced thermal expansions, important effects of indirect fire actions could perhaps also evolve in large-span RC structures although RC members are normally more massive and although concrete has lower thermal conductivity. Thus, such actions might only evolve in exceptional situations. The latter is a matter of further investigation.

\section{Acknowledgements}

J. Č. Kolšek and P. Česarek acknowledge support of the Slovenian Research Agency, research core fundings No. P2-0158 and No. P2-0260.

\section{Appendix A. Time fluctuations of $H, V$ and $M$}

This section discusses time evolution of indirect fire actions $H$, $V$ and $M$ as observed in this paper.

\section{A.1. Time fluctuations of $V$}

At room temperature as well as during the fire $V$ is governed purely by the gravitational loads of the beam and the rotational stiffness of the beam's left (clamped) and its right (bolted) end. The latter is varying constantly which is a direct result of gradual plastifications of steel evolving around the beam's ends (de- 
scribed in Section 4.1). The redistributions of vertical reaction forces acting on the beam at its ends from one of these ends towards another follow closely (Fig. A.17). A direct consequence are time fluctuations of $V$ (Fig. A.18).

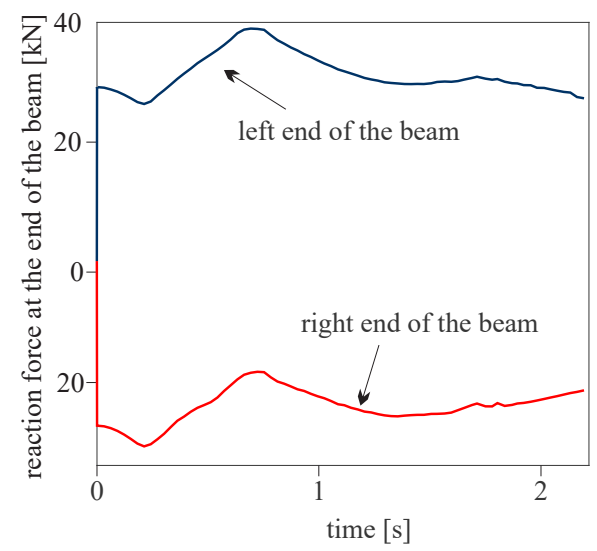

Fig. A.17: Variation of vertical reaction forces as evolving with time at the ends of the beam of FCE building. Notice that their sum is remaining constant over time.

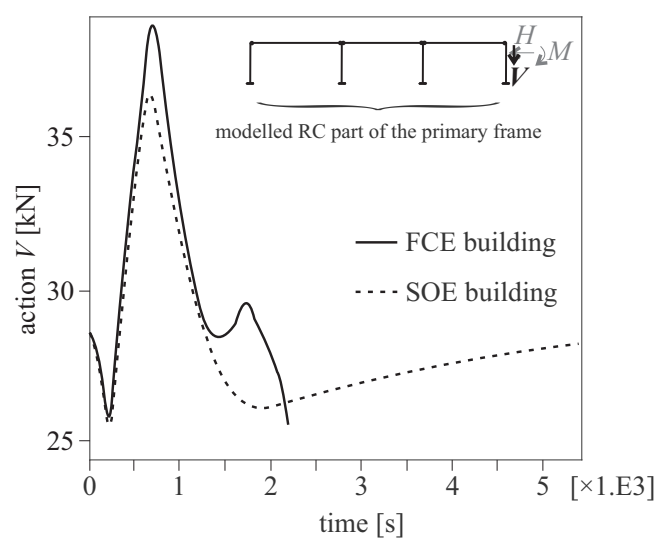

Fig. A.18: Action $V$ as evolving with time in FCE and SOE building.

\section{A.2. Time fluctuations of $M$}

At room temperature the value of $M$ is governed purely by gravitational forces of the structure and by the initial rotational stiffness of the beam's ends. After the start of the fire, however, the value of $M$ at a specific time will further depend also on:

- cross-sectional difference in steel temperature (causing an increase of $M$ ):

Three-sided fire exposure of the beam will cause its lower flange and its web to have higher temperature at a specific time compared to its upper flange. This means that the tendency of the beam for thermal elongation will be higher in the lower parts of its cross-section. Within this region, however, the actual elongation of the beam will be hindered by the colder upper parts of the beam as well as by its end supports. Variations of stress across the cross-section and correspondingly an additional bending moment will be induced.

- gradual uplifts of the right end of the steel beam (causing a decrease of $M$ ):

This will be caused by thermal elongation of the connected steel column.

- redistribution of reaction forces and reaction moments at the beam's ends (causing an increase of $M$ at first and its decrease later):

As already discussed above (see A.1.), redistributions of reaction forces and moments from one of the beam's ends towards another are evolving constantly during the fire because of gradual plastifications of steel evolving around the beam's ends. In a simplified manner one could say that with these plastifications the mechanical response of the beam, which is before the fire similar to behaviour of a both-side clamped structural member, gradually moves towards behaviour of a beam with a clamped left and a pinned right end (action $M$, and also action $V$, are gradually increasing during this time). After that the response of the beam starts moving closer to a behaviour of a both-side pinned member ( $M$ and $V$ are decreasing).

Since in general the value of $M$ is higher compared to its ambient-temperature value for most of the fire duration, it is obvious that for both of the analysed cases (SOE and FCE budiling) the second among the above three listed effects is of minor importance. Regarding the remaining effects, the third one seems to prevail the first one (see Fig. A.19).

\section{A.3. Time fluctuations of $H$}

Action $H$ revolves around the degree of restriction of the beam's thermal elongation. The latter depends on structural conditions at both of the beam's ends and strength of the material pushing towards these ends, both of which, as everything else, are changing over time. In general $H$ (Fig. A.20) is increasing fast at first and starts decreasing later, i.e. after the average temperature in the beam reaches about $450^{\circ} \mathrm{C}$ (temperature of sudden pronounced loss of material strength, see e.g. [2]).

Nevertheless, for FCE building, a local decrease of $H$ is also observed around the 5th minute of the fire. This is a direct effect of first plastifications of the steel clamp connecting the steel beam to the RC column on its left which are formed around this time and are causing a sudden accelerated growth of a visible gap between partitions of both structural members (see Fig. 


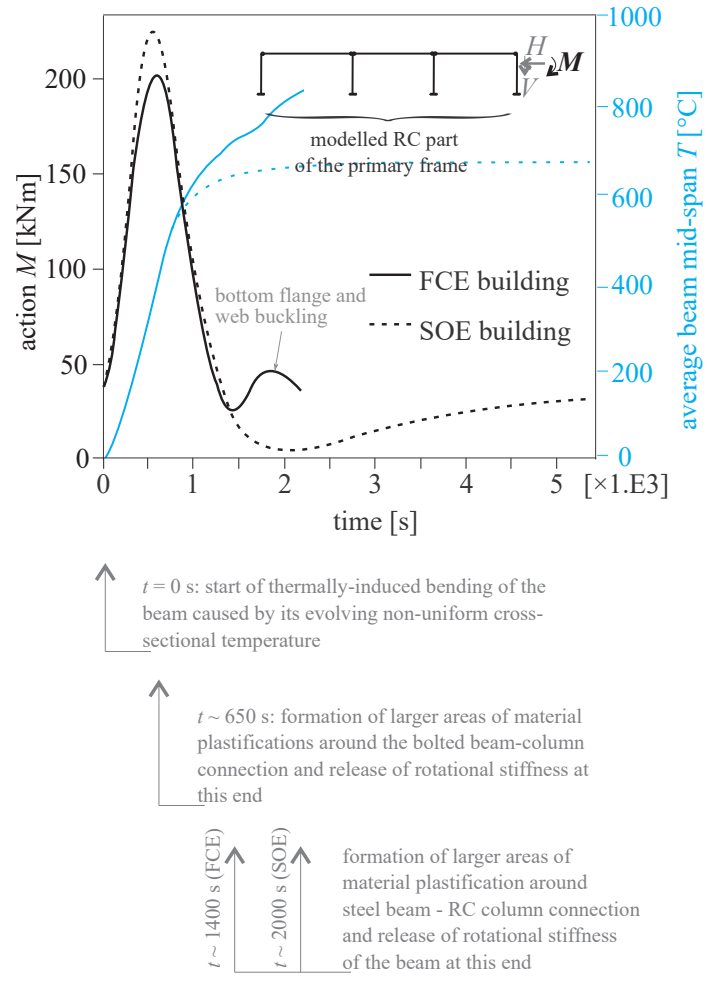

Fig. A.19: Action $M$ as evolved with time in FCE and SOE building.

A.21). ${ }^{13}$ The latter suddenly allows the upper parts of the beam to elongate more freely. Correspondingly, force $H$ drops noticeably. Although such gap is also formed in case of SOE building, its growth is much slower here because plastifications of the clamp are somewhat delayed in this case and are only evolved after the elapsed 10th minute. At this time action $H$ already decreases on account of sudden pronounced loss of strength of the material. The reason behind the discussed delay is distinctions in thermal boundary conditions. Recall that in SOE building the facade of the steel-framed extension is considered open, thus, for the fire situation, the steel column is assumed to have a four-sided fire exposure (in contrast to FCE building where three-sided exposure is assumed). Consequently, it heats and elongates faster in this case (Fig. A.22). More elongation of the column means more uplift of the right end of the beam which contradicts the progression of the gap (Fig. A.22).

\section{References}

[1] EN 1991-1-2: Eurocode 1: Actions on structures - Part 1-2: General actions - Actions on structures exposed to fire. European Committee for Standardization, 2002.

[2] EN 1993-1-2: Eurocode 3, Design of steel structures, Part

\footnotetext{
${ }^{13}$ The gap as seen in Fig. A.21 is not only a consequence of mechanical deformations of steel clamp but also of its thermal expansion (bear in mind that steel clamp heats to higher temperatures and expands faster as the RC column).
}
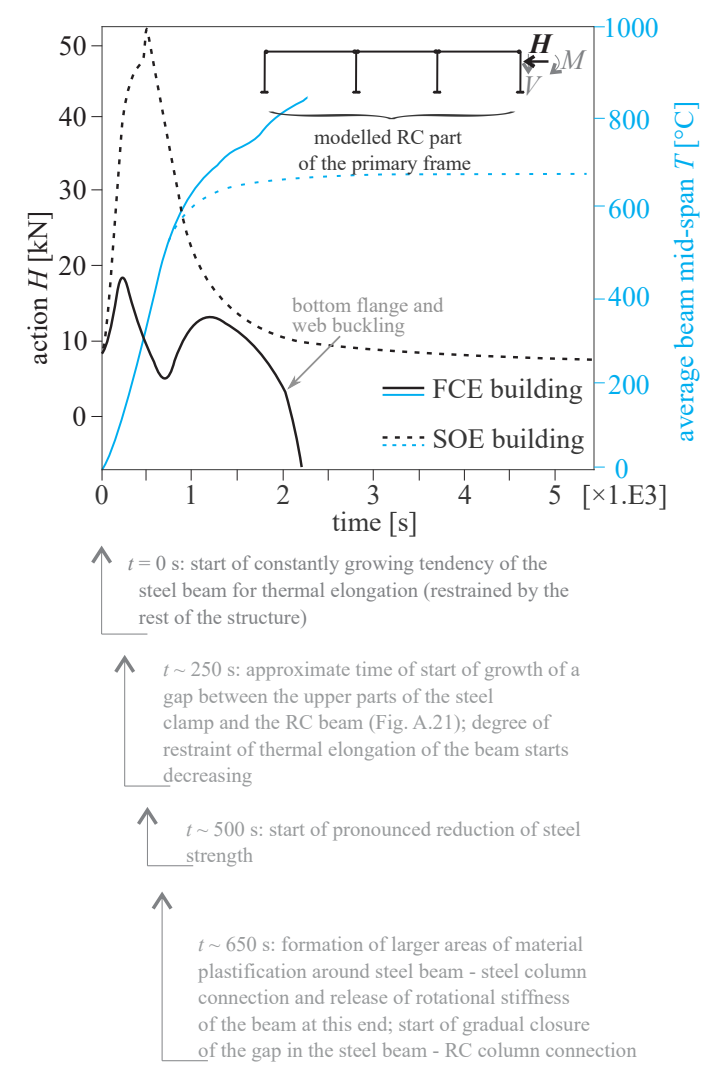

Fig. A.20: Action $H$ as evolved with time in FCE and SOE building.

1.2: Structural fire design. European Committee for Standardization, 2004.

[3] J. Kolšek, I. Planinc, M. Saje, and T. Hozjan. The fire analysis of a steel-concrete side-plated beam. Finite Elem Anal Des, 74:93-110, 2013.

[4] G.-Q. Li and C. Zhang. Creep effect on buckling of axially restrained steel columns in real fires. J Constr Steel Res, 71:182-188, 2012.

[5] S. Foster, M. Chladna, C. Hsieh, I. Burgess, and R. Plank. Thermal and structural behaviour of a full-scale composite building subject to a severe compartment fire. Fire Saf J, 42:183-199, 2007.

[6] V. K. R. Kodur and M. M. S. Dwaikat. Response of steel beam-columns exposed to fire. Eng Struct, 31:369-379, 2009.

[7] G. Srivastava and P.R. Prakash. An integrated framework for nonlinear analysis of plane frames exposed to fire using the direct stiffness method. Comput Struct, 290:173$185,2017$.

[8] M. Zhou, R.P.R. Cardoso, H. Bahai, and A. Usmani. A 


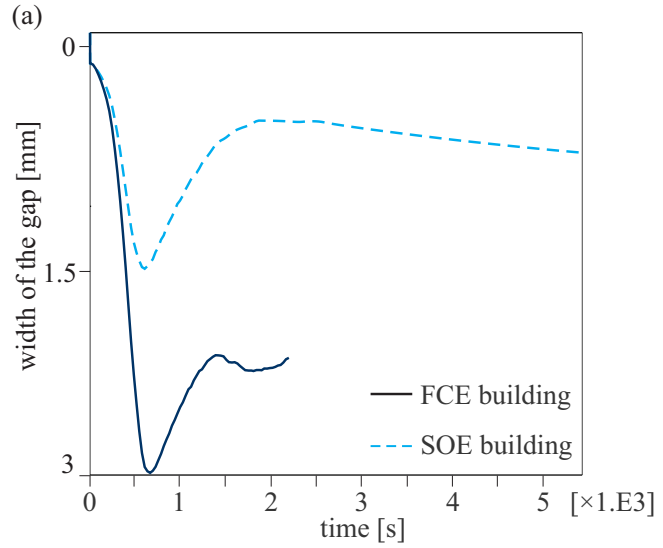

(b)

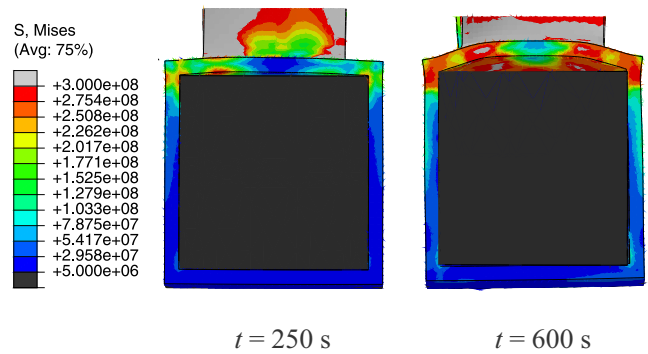

Fig. A.21: Growth of the gap between the steel clamp and the $\mathrm{RC}$ column. In figure b) deformations of the clamp are scaled 10-times. Mises stress is in $\mathrm{N} / \mathrm{m}^{2}$.

thermo-mechanical analysis of stainless steel structures in fire. Eng Struct, 210, 2020.

[9] C. Qin and H. Mahmoud. Collapse performance of composite steel frames under fire. Eng Struct, 183:662-676, 2019.

[10] L. Possidente, N. Tondini, and J.M. Battini. 3d beam element for the analysis of torsional problems of steelstructures in fire. J Struct Eng, 146, 2020.

[11] C. Maraveas, T. Gernay, and J.M. Franssen. An equivalent stress method to account for local buckling in beam finite elements subjected to fire. J Struct Fire Eng, 10:340-353, 2019.

[12] M. Malendowski, A. Glema, Z. Kurzawa, and L. Polus. Mechanical response under natural fire of barrel shape shell structure. J Struct Fire Eng, 6:59-66, 2015.

[13] V. K. R. Kodur and M. M. S. Dwaikat. Effect of high temperature creep on the fire response of restrained steel beams. Mater Struct, 43:1327-1341, 2010.

[14] Z.W. Yu, C. Lu, and Y.Q. Zhong. Performance-based analysis of single-layer cylindrical steel reticulated shells in fire. Appl Sci-Basel, 10, 2020.

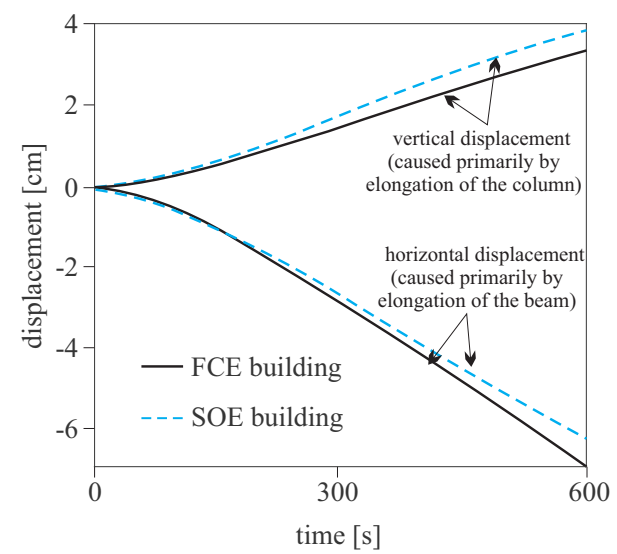

Fig. A.22: Horizontal and vertical displacements of the top of the steel column during the first 10 minutes of the fire. Because at the very top (region between both continuity plates) first plastifications of steel already appear before the elapsed 10th minute, the displacements are shown for a somewhat lower position.

[15] S.Z. Lu, W. Wang, W.D. Chen, J.X. Ma, Y.Q. Shi, and C.L. Xu. Behaviors of thin-walled cylindrical shell storage tank under blast impacts. Shock Vib, 2019, 2019.

[16] Aldina Santiago, Luis Simes da Silva, Paulo Vila Real, and Milan Veljkovic. Numerical study of a steel sub-frame in fire. Comput Struct, 86:1619-1632, 2008.

[17] A. Rebec, J. Kolšek, and P. Plešec. Fires in storages of LFO: Analysis of hazard of structural collapse of steelaluminium containers. J Hazard Mater, 306:367-375, 2016.

[18] M. E. Garlock and S. Selamet. Modeling and behavior of steel plate connections subject to various fire scenarios. $J$ Struct Eng, 136:897-906, 2010.

[19] S. Selamet and M. E. Garlock. Fire resistance of steel shear connections. Fire Saf J, 68, 2014.

[20] S. Selamet and C. Bolukbas. Fire resilience of shear connections in a composite floor: Numerical investigation. Fire Saf J, 81, 2016.

[21] P. Češarek, M. Kramar, and J. Kolšek. Effect of creep on behaviour of steel structural assemblies in fires. Steel Compos Struct, 29:423-435, 2018.

[22] T. Scullion, F. Ali, and A. Nadjai. Finite element numerical evaluation of elliptical hollow section steel columns in fire. Thin Wall Struct, 55:22-36, 2012.

[23] Y.D. Li and J.C. Zhao. Modelling of bolted endplate connections subjected to bending moment and axial force in fire. KSCE J Civ Eng, 22:4977-4987, 2018. 
[24] H. Mahmoud, B. Ellingwood, C. Turbert, and M. Memari. Response of steel reduced beam section connections exposed to fire. J struct Eng, 142, 2016.

[25] V. Kodur and A. Arablouei. Mechanics-based approach for modeling delamination of fire insulation from steel structures. J Eng Mech, 140, 2014.

[26] J. P. C. Rodrigues, I. C. Neves, and J.C. Valente. Experimental research on the critical temperature of compressed steel elements with restrained thermal elongation. Fire Saf $J, 35,2000$.

[27] X. Feng and L. YanPing. Criteria of limiting temperature and parametric analysis of the large deflection behavior for fully restrained steel beams in fire. Sci China Technol Sc, 55, 2012.

[28] T. C. H. Liu, M. K. Fahad, and J. M. Davies. Experimental investigation of behavior of axially restrained steel beams in fire. J Constr Steel Res, 58, 2002.

[29] G. Q. Li and S. X. Guo. Experiment on restrained steel beams subjected to heating and cooling. J Constr Steel Res, 64, 2008.

[30] C. Zhang, G.-Q. Li, and A. Usmani. Simulating the behavior of restrained steel beams to flame impingement from localized-fires. J Constr Steel Res, 83, 2013.

[31] A.S. Usmani, D.D. Drysdale, J.M. Rotter, A.M. Sanad, M. Gillie, S. Lamont, M.A. O’Connor, D. O’Callaghan, A.Y. Elghazouli, B.A. Izzuddin, A.J. Richardson, C.G. Bailey, and G.M. Newman. PIT Project - Behaviour of steel framed structures under fire conditions (main report). The University of Edinburgh, 2000.

[32] F. Wald, L. S. da Silva, D.B. Moore, T. Lennond, M. Chladna, A. Santiago, M. Beneš, and L. Borges. Experimental behaviour of a steel structure under natural fire. Fire Saf J, 41, 2006.

[33] F. Hanus. Calculation of internal forces in axially and rotationally restrained beams under natural fire. Université de Liège, 2008.

[34] J. Kolšek. Comparison of simplified and advanced simulation of a fire in a factory of xps panels. Adv Mater Appl, $1147: 30-35,2018$.

[35] J. Kolšek and P. Češarek. Performance-based calculation of fire load of a structure of a XPSfactory fire. 40th Congress of Structural Designers of Slovenia, 19th-20th November 2018, Bled, Slovenia:171-178 (in Slovene), 2018. URL https://www.researchgate.net/publication/351391060
An_example_of_performance-based_calculation_of_the_ fire_load_of_a_structure_in_a_XPS-factory_fire.

[36] F. M. Block, J. B. Davison, I. W. Burgess, and R. J. Plank. Principles of a component-based connection element for the analysis of steel frames in fire. Eng Struct, 49:10591067, 2013.

[37] C. Maraveas, T. Gernay, and J.M.Franssen. An equivalent stress method to account for local buckling in beam finite elements subjected to fire. J Struct Fire Eng, 10, 2019.

[38] T. Gernay and J.M.Franssen. The introduction and the influence of semi-rigid connections in framed structures subjected to fire. Fire Saf J, 114, 2020.

[39] M. M. S. Dwaikat and V. K. R. Kodur. A performance based methodology for fire design of restrained steel beams. J Constr Steel Res, 67:510-524, 2011.

[40] EN 1992-1-2: Eurocode 2, Design of concrete structures, Part 1.2: Structural fire design. European Committee for Standardization, 2004.

[41] EN 1990: Eurocode 0: Basis of Structural Design. European Committee for Standardization, 2002.

[42] SIST EN 1990:2004/A1:2006/A101:2009: Eurocode - Basis of Structural Design - National Annex. European Committee for Standardization, 2002.

[43] EN 1992-1-1: Eurocode 2, Design of concrete structures, Part 1.1: General rules and rules for buildings. European Committee for Standardization, 2004.

[44] B. R. Kirby. The behavior of high-strength grade 8.8 bolts in fire. J Constr Steel Res, 33:3-8, 1995.

[45] Y. Anderberg. Modeling steel behaviour. Fire Safety J, 13:17-26, 1988.

[46] J. C. Simo and T. J. R. Hughes. Computational inelasticity. Springer, New York, 1998.

[47] K. W. Poh. Stress-strain-temperature relationship for structural steel. J Mater Civil Eng, 13:371-379, 2001.

[48] K. W. Poh. Stress-strain-temperature relationship for structural steel (vol 13, pg 371, 2001). J Mater Civil Eng, $26: 388-389,2014$

[49] G. Williams-Leir. Creep of structural-steel in fire - analytical expressions. Fire Mater, 7:73-78, 1983.

[50] W. E. Luecke, J. D. McColskey, C. N. McCowan, S. W. Banovic, R. J. Fields, T. Foecke, T. A. Siewert, and F. W. Gayle. Federal Building and Fire Safety Investigation of the World Trade Center Disaster: Mechanical Properties 
of Structural Steels. NIST National Institute of Standards and Technology, Technology Administration, U. S. Department of Commerce, U. S. Government Printing Office, Washington, DC, USA, 2005.

[51] EN 1363-1:2012. Fire resistance test. General requirements. European Committee for Standardization, Brussels, 2012.

[52] EN 1998-1: Eurocode 8, Design of structures for earthquake resistance - Part 1: General rules, seismic actions and rules for buildings. European Committee for Standardization, 2004.

[53] B. Kralj. Impact of a Fire in the Planned Steel Frame Extension on a Load-bearing Capacity of an Existing Reinforced Concrete Frame Structure. University of Ljubljana, Faculty of Civil an Geodetic Engineering, Master's Thesis - 2nd Degree Studies, 2019 (in Slovene). URL https://repozitorij.uni-lj.si/IzpisGradiva.php?id=109346.

[54] J. Kolšek and P. Češarek. Performance-based fire modelling of intumescent painted steel structures and comparison to EC3. J Constr Steel Res, 104:91-103, 2015. 